\title{
Hands-on optics and photonics outreach in Riga
}

Natalija Lesina, Janis Spigulis

Natalija Lesina, Janis Spigulis, "Hands-on optics and photonics outreach in Riga," Proc. SPIE 9289, 12th Education and Training in Optics and Photonics Conference, 92892I (17 July 2014); doi: 10.1117/12.2070737

SPIE Event: 12th Education and Training in Optics and Photonics Conference, 2013, Porto, Portugal 


\title{
Hands-on optics and photonics outreach in Riga
}

\author{
Natalija Lesina, Janis Spigulis \\ Institute of Atomic Physics and Spectroscopy, University of Latvia, Riga, Latvia \\ natalija.lesina@lu.Iv
}

\begin{abstract}
A long-term exposition focused on optics and photonics was created in Institute of Atomic Physics and Spectroscopy at University of Latvia in 2010.

Considering unpopularity of science in Latvia and lack of broadly accessible hands-on outreach activities for school children, as well as rapid development of advanced photonic technologies, this exposition was meant to involve more students to the natural sciences and modern technologies.

Exposition covers 10 topics of optics - colors, diffraction, interference, polarization, reflection, liquid crystals, gas discharge, lasers, fluorescence, infrared and ultraviolet radiation.

Students' visits are organized as an exciting adventure, which differs from ordinary school lessons. The visit mainly includes own actions with hands-on exhibits, lecturer's explanations about the most difficult topics and some demonstrations shown by the lecturer. The main accent is made on hands-on experiments due to the fact that students, who had performed hands-on experiments, will be emboldened to choose their career in the field of science and technologies.

The exposition now is running and is part of Riga Photonics Center. Nearly 300 students from the $8^{\text {th }}$ till $12^{\text {th }}$ grades visited it during academic years 2011/2012 and 2012/2013 and their generally positive feedback has been analyzed.
\end{abstract}

\section{INTRODUCTION}

"Physics is not interesting!" The phrase which is heard very often by school physics teachers. That is true - to students' opinion physics is incurious, tough and tedious ${ }^{1}$. Furthermore students do not link physics and science itself with the real life and think that there is no connection at all.

Taking into account poor popularity of physics and science among students in Latvia, a long time exposition focused on optics and photonics outreach was established in Institute of Atomic Physics and Spectroscopy (IAPS) at University of Latvia and approbated during academic year 2010/2011. Approbation results ${ }^{2}$ showed that exposition is interesting and needed in Riga. Now the exposition is part of Riga's Photonics Center which was launched within the project FOTONIKA-LV.

During visit not only simple demonstrations on optics are being shown, but also some experiments which are performed in IAPS for research are being demonstrated with explanations how they can be implemented in real life.

Optics is very attractive and that is why it is very appropriate for demonstrations on purpose of science popularization. Also it is believed that students who had performed hands-on experiments will be encouraged to choose their further education in the field of science comparing to them who had not ${ }^{3}$.

In this paper new results are showed and analyzed.

\section{METHODOLOGY}

The exposition is not only entertaining where students perform some experiments without understanding what is happening and what kind of optical phenomenon lies under it how it sometimes happens in science museums, but it has educative intent. Lecturer is explaining all optical phenomena which take place in each experiment. Exposition is conditionally divided in three parts depended on human senses - audition, vision and touch. On educational purpose it is necessary to cover all senses because different people perceive information in different ways. Audition is involved during comprehensive lecturer's explanations, vision - when lecturer is demonstrating experiments, touch - most relevant part, when students perform hands-on experiments. All these parts are not strictly detached but conversely they are integrated into each other ensuring that all students are interested in action.

12th Education and Training in Optics and Photonics Conference, edited by

Manuel F. P. C. Martins Costa, Mourad Zghal, Proc. of SPIE Vol. 9289, 92892I

(C) 2014 SPIE, OSA, IEEE, ICO· doi: 10.1117/12.2070737 
Using different demonstrations and hands-on exhibits 9 topics of optics - colors, diffraction, polarization, reflection, interference, fluorescence, infrared and ultraviolet radiation, gas discharge and lasers - are covered. All topics are overlapping each other. Brief overview of each topic is described below.

\section{Colors}

This is first topic which is devoted to colors formation from white light. Using triangle glass prism the formation of rainbow is being discussed. Using filters it is being showed, how one can get one colored light with explanation that others are absorbed by the filter. Since one can split white light into spectra, it is possible to combine it back. Using three lasers (red, green, blue) and side-emitting optical fiber it is being showed how light colors are formed, combining them in pairs and finally getting back white light switching all lasers on. Also red-green 3D glasses are being used to demonstrate humans' perception of colors.

In this topic the concept of wavelength is introduced due to its necessity in other topics.

\section{Diffraction}

The phenomenon of diffraction can show that white light is not actually white. Using different diffraction gratings students can observe white light spectra looking through it. It is being explained what the diffraction grating is and how does it work. Using different wavelength lasers it is being showed how diffraction pattern depends on wavelength. Students can observe the usage of reflective diffraction grating in an open monochromator.

\section{Interference}

The Michelson interferometer for educational purposes is being used to show and explain the phenomenon of interference. Students are asked to adjust it after they have seen the correct pattern. The usage of interference is being showed on antireflective coatings.

\section{Polarization}

The phenomenon of polarization also allows demonstrating white lights colorful world. Before students start to investigate the polarizers the behavior of electromagnetic wave is being explained, terms of polarized and nonpolarized light are determined. Next step is to make improvised polariscope from two perpendicularly placed linear polarizers. By putting a transparent object between them one can observe colors. It is being explained why one can see colors. Also students can explore how their glasses change transparency putting those between polarizers.

\section{Reflection}

Using flat mirrors, protractors, string, laser and target students can test the rule of reflectance. Total internal reflection is being explained as well. Students can test it using Ulexite crystal and manufactured optical fibers.

\section{Liquid crystals}

The demonstration of liquid crystals shows another way of reflectance, colors and interference phenomena. Using sheets of encapsulated liquid crystals students are investigating selective reflectance.

\section{Infrared and Ultraviolet radiation}

IR and UV radiation is being discussed as another form of electromagnetic radiation different from white light. Using specially designed camera students take pictures of themselves in infrared light, also pictures of hidden objects can be taken.

UV radiation basically is being used to initiate fluorescence. Applications and noxiousness of UV radiation also are being discussed.

\section{Gas discharge}

This optical phenomenon is being presented using electrodless discharge lamps filled with different chemical elements. Putting the lamp in solenoid with high frequency alternating current in it, the gas is being excited and one can observe emission of different colors. This demonstration for safety reasons is being only showed by the lecturer, but students can explore analogical phenomenon using plasma ball.

\section{Lasers}

In this topic the main principles of lasers' construction is being explained. The main reason for this topic is to show and explain students that laser is serious and complicated facility not only pen sized pointer. Gas laser, solid state laser, diode laser, three color laser projector are being showed and as mentioned previous used in other demonstrations. 


\section{Fluorescence}

In this topic it is being explained that some substances and materials can emit luminescent light if they are stimulated by external source of energy. To show the phenomenon of fluorescence lasers and UV lamps are being used for fluorescence excitation and fluorescence testing cards, Rhodamine liquid, minerals are being used as specimens. Chemically induced fluorescence also is being showed. Difference between phosphorescence and fluorescence is being explained.

\section{RESULTS}

270 students from the $8^{\text {th }}$ to $12^{\text {th }}$ grades visited exposition during academic years 2011/2012 and 2012/2013. After the visits they were asked to fill the questionnaire about the visit.

To summarize and analyze their feedback they were divided into two groups:

1. $8^{\text {th }}$ to $11^{\text {th }}$ grades;

2. $12^{\text {th }}$ grade.

The division is made according to curriculum of physics in Latvia, where topic of optics is being taught in $8^{\text {th }}$ and $12^{\text {th }}$ grade, from which it follows that one can assume that basic knowledge about optics is quite similar in $8^{\text {th }}$ to $11^{\text {th }}$ grade.

In questionnaire students were asked to mark in scale 1-5 (where 1 is the best, 5- the worst) how interesting and understandable was each topic, what kind of activity did they enjoy the best and about necessity of exposition in Riga.

\section{$8^{\text {th }}$ to $11^{\text {th }}$ grades}

126 students from $8^{\text {th }}$ to $11^{\text {th }}$ grades visited the exposition.

$91 \%$ of them enjoyed the visit, $2 \%$ did not enjoy the visit and $7 \%$ did not answer this question.

$96 \%$ think that it is necessary to have place like this in Riga. The main reasons were mentioned: enjoyed handson experiments; it is interesting; it is something new.

In Fig. 1 one can observe $8^{\text {th }}$ to $11^{\text {th }}$ grades students' opinion about the activity. It is noticeable that only $21 \%$ of students better prefer hands-on activities while $68 \%$ like looking.

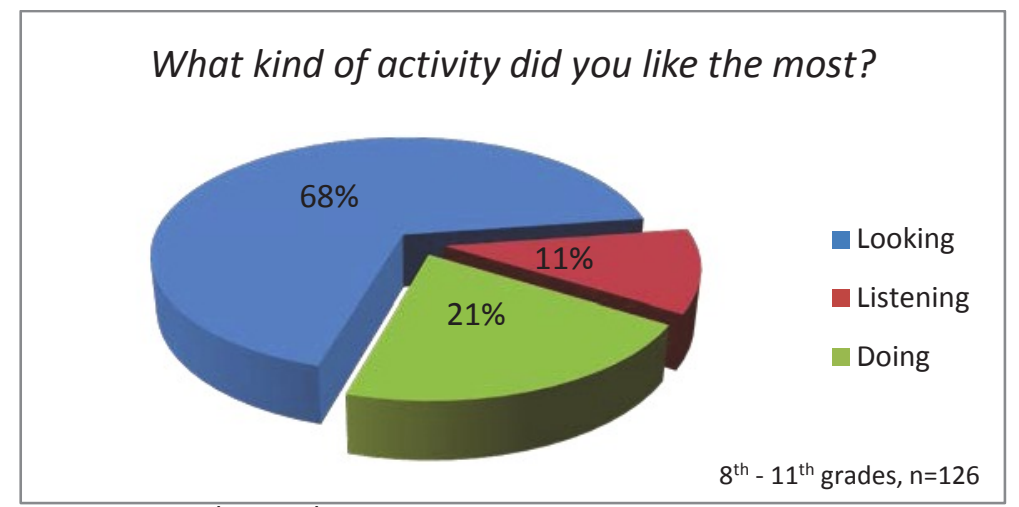

Fig.1. $8^{\text {th }}$ till $11^{\text {th }}$ grades students' responses about the activity

In Fig. 2 one can observe students' evaluation for each topic covered in exposition. Topics Lasers, Gas discharge and Polarization were the most interesting, while Interference thought to be more boring. It is noticeable that Interference was considered as the hardest topic, while Lasers was the most understandable. Authors assume that there is correlation between "like" and "understand" and vice versa, because knowledge in optics is very poor. And this might be reason why physics is not interesting for students. 


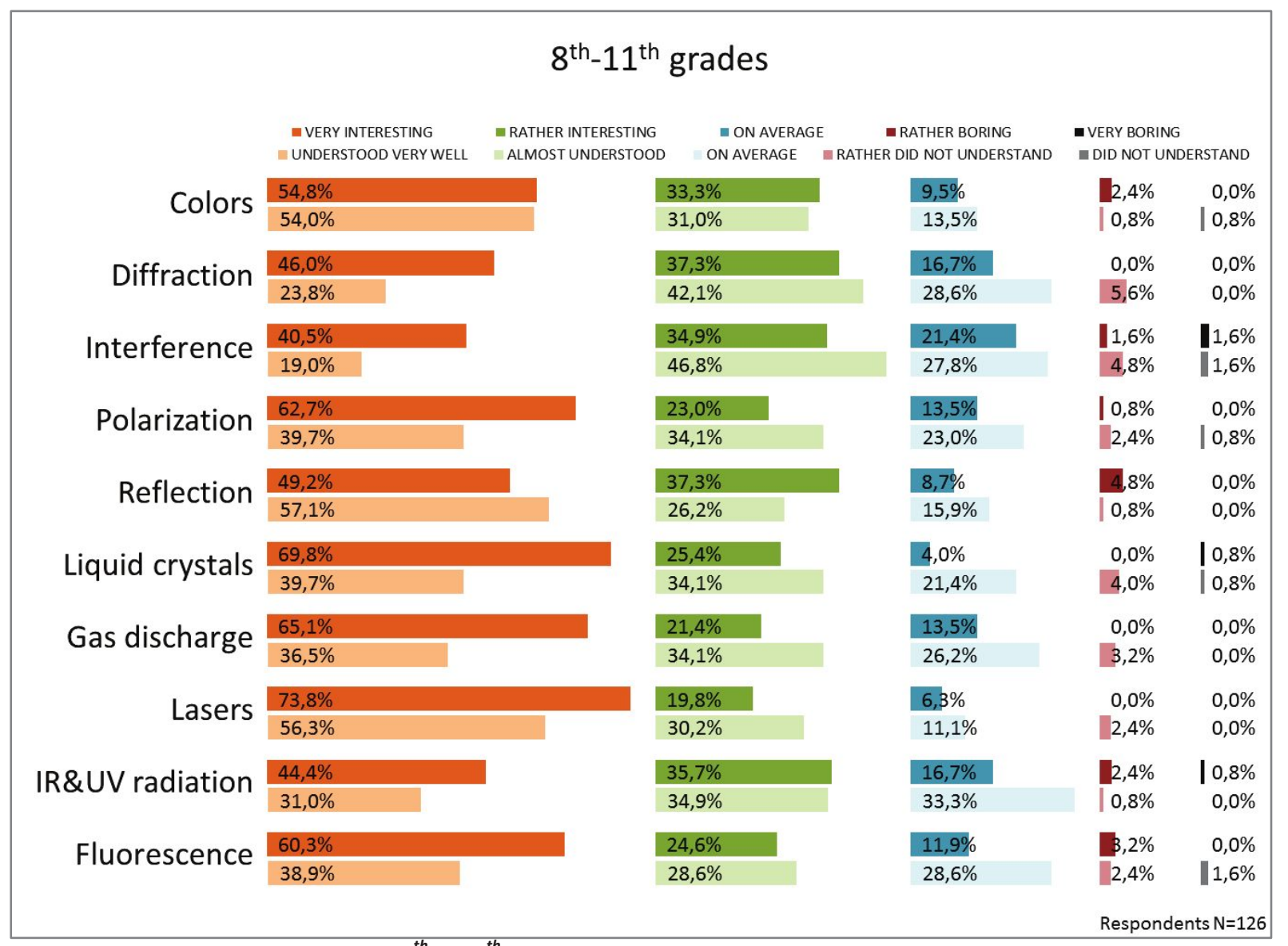

Fig.2. $8^{\text {th }}$ to $11^{\text {th }}$ grades students' evaluation for each topic

\section{$12^{\text {th }}$ grade}

144 students of $12^{\text {th }}$ grade visited the exposition.

$97 \%$ of them enjoyed the visit, $3 \%$ did not answer this question.

$100 \%$ think that it is necessary to have place like this in Riga. The main reasons were mentioned: enjoyed handson experiments; it is useful; it gives deeper knowledge.

In Fig. 3 one can observe $12^{\text {th }}$ grade students' opinion about the activity. It is noticeable that only $25 \%$ of students better prefer hands-on activities while $67 \%$ like looking.

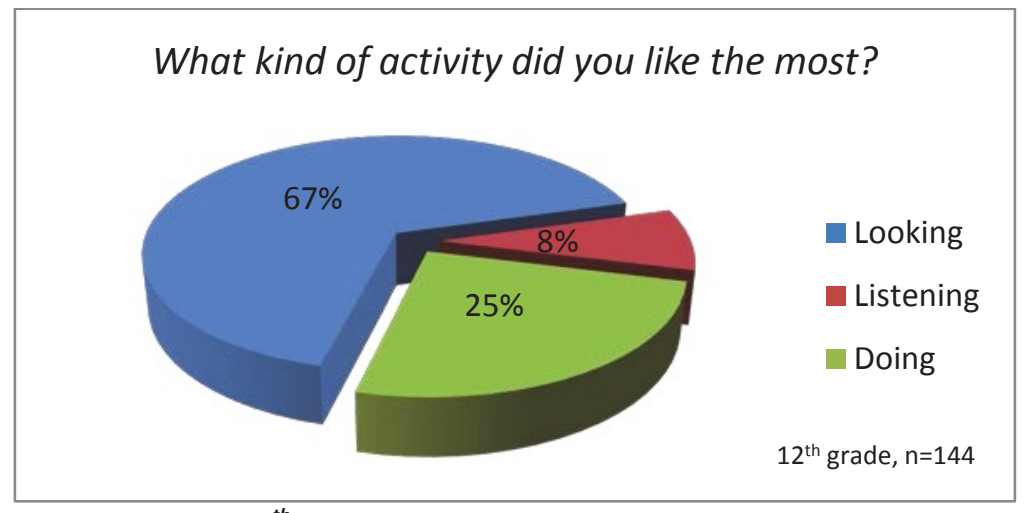

Fig.3. $12^{\text {th }}$ grade students' responses about the activity 
In Fig. 4 one can observe students' evaluation for each topic covered in exposition. Topics Lasers, Fluorescence and Colors were considered as most interesting, while topic Reflection most boring. Here one can also see correlation between "like" and "understand". But in this group correlation is not so evident. For example, if one looks at the topic Reflection, it is very well understood, but no interesting. Authors assume that, when knowledge in optics increases, interesting and understandable things become better distinguishable, and students can more critically evaluate their knowledge.

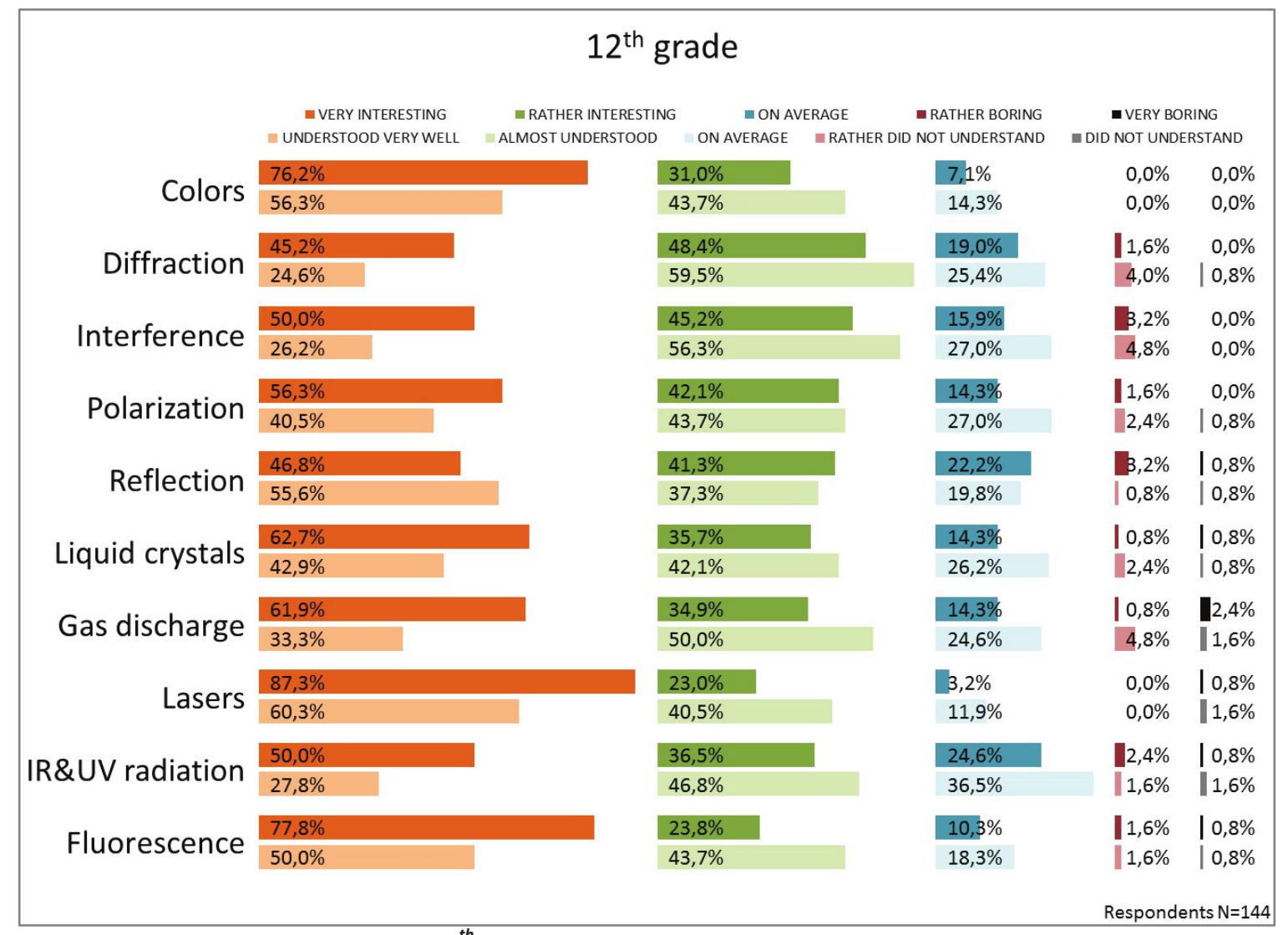

Fig.4. $12^{\text {th }}$ grade students' evaluation for each topic

In both groups questionnaire showed that students better prefer "looking" instead of "doing". To authors' assumption the reason for this paradox (paradox because students pointed out that hands-on experiments is the main reason why exposition of this kind is necessary in Riga) is that students nowadays are keen on modern technologies, like smart phones, 3D television etc. This means that the only activity is looking and they got used to it.

\section{CONCLUSIONS AND DISCUSSION}

Taking into account different knowledge background of these two groups, results shown in current work are reliable and may be taken into account planning further work in Riga's Photonics Center, as well as used by teachers planning their school lessons.

Also one cannot neglect that to achieve better results in students' involving into the science more hands-on curricula should be implemented in school lessons. To authors' opinion students should perform more hands-on experiments with the aim to make them think about things they are doing and encourage them to choose studies in the field of science. 
To emphasize the significance of photonics, school teachers and outreach experts should stress that part of new technologies are based on principles and phenomena of optics, present new results and achievements in the field of photonics.

\section{ACKNOWLEDGEMENTS}

Support from FP7 project Unlocking and Boosting Research Potential for Photonics in Latvia - Towards Effective Integration in the European Research Area (FOTONIKA-LV), FP7-REGPOT-CT-2011-285912, and SPIE Educational Outreach grant, as well as tangible support from OSA are highly appreciated.

\section{REFERENCES}

[1] Foreman, H.,D., Parmigiani, F.,R., Roelens, M.A.F., \& Simson, R.,E. "The Lightwave Roadshow", In: 9th international ETOP confernece, 140-148, 2005

[2] Lesina, N., Spigulis, J., "Hands-on approach to informal education on optics and photonics", In: $8^{\text {th }}$ International IOSTE Symposium for Central and Eastern Europe, 138-144, 2011

[3] Mc Hugh, E., Smith, A., Optics outreach in Irish context. In: 11-th international ETOP confernece, p. 114-120, 2009 